\title{
The Effects Of Africentric United States History Curriculum On Black Student Achievement
}

\author{
Worokya Duncan, Ed.D., Duncan Educational Consultants, LLC, USA
}

\begin{abstract}
Relationships between United States History curriculum design, self-efficacy, and test achievement of eighth-grade students and parents in the KIPP:STAR College Preparatory Charter School were examined in this study. An online questionnaire developed for the study, the Parental Questionnaire for United States History Curriculum, was pilot tested, revised, and used to collect data. Collected data were analyzed using the SPSS (v.19) software. Descriptive statistics and frequencies regarding curricular design, test achievement, and self-efficacy were examined. Results revealed a need for an Africentric United States history curriculum, which by definition is more inclusive and comprehensive than the normative Eurocentric curriculum. The mixed-method study indicated that relationships exist between curricular design and test achievement and between curricular design and self-efficacy.
\end{abstract}

Keywords: History Curriculum; Black Student Achievement; Standardized Testing; Achievement Gap

\section{INTRODUCTION}

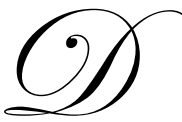

espite the ethnic changes in the population of the United States during the last 40 years, education has continued to be based upon a traditional Eurocentric model (Darling-Hammond, 2010). Black students have scored disproportionately lower on assessments of higher order thinking skills, such as standardized social studies examinations, due to cultural insensitivity in instruction, poor instruction, minimally qualified teachers, and weak literacy instruction (Zwick \& Green, 2007). However, a recent study conducted at KIPP: Star College Preparatory School in Harlem, New York, showed the positive effects of an Africentric U.S. history curriculum on students' standardized test scores, perceptions of self-efficacy, and emotional attachment to the curriculum.

\section{AFRICENTRIC VS. EUROCENTRIC EDUCATION}

Africentrism is the written expression of indigenous African ideology as personified by the lived experiences of generations of people within the African diaspora. Africentrism is guided by common African principles to empower and validate African diasporic history and knowledge. Asante (2008) defined Africentric as the conscious choice to position oneself within the historical narrative by using Africa as the perspective. His perspective was not race sensitive; rather, individuals of European descent were considered race-less (Asante, 2003).

Eurocentrism is the implicit assumption that all relevant modern concepts, practices, technologies, and capacities are essentially European. North American public education rests on a Eurocentric foundation, as does the reiteration of what instructors consider legitimate knowledge through items on standardized examinations. Any philosophy or ideology opposing the centrality of European dominance and superiority has been judged as deviant by the dominant educational culture.

While individuals with Africentric perspectives believe that education should result in self-sufficient, resourceful people who first look within their own culture instead of without for primary confirmation (Abdi, 2006). Education in the United States, at least for children of the African diaspora, has long been the opposite. 


\section{KIPP: STAR COLLEGE PREPARATORY SCHOOL}

The KIPP: STAR (Success Through Teamwork, Achievement, and Responsibility) College Preparatory School in Harlem, New York, for Grades 5-8, was founded in 2003 by seven teachers. The school operates under five tenets: (a) choice and commitment, (b) high expectations, (c) extended school days and school year, (d) focus on results, and (e) power to lead. The aim of the school is to improve the educational experiences of Harlem students through fostering an environment conducive to higher order thinking skills, implementing a liberal yet rigorous curriculum, and following the five tenets (KIPP Foundation, 2008).

The students at KIPP: Star are African, Black, Hispanic, and Latino in ethnicity; most of them qualify for the free and reduced-price lunch program (KIPP Foundation, 2008). The combination of gentrification and rezoning in Harlem has resulted in forcing students who begin in poor schools to remain in poor schools. Although the students at KIPP: Star have historically outperformed students at the other public, private, and charter schools within the district on mathematics and language arts standardized examinations, creating curriculum to inspire through cultural relevancy is vital to helping these students succeed academically.

\section{DEVELOPMENT OF AN AFRICENTRIC U.S. HISTORY CURRICULUM}

Debate concerning what should be taught in U.S. history has been fiery. Traditionalists have favored the Eurocentric view, citing a need to maintain American ideas, institutions, and history. Reformists have desired to address and redress anti-woman sentiments and marginalization of minorities in history curricula. James's (2007) study on Africentric, Eurocentric, and multicultural curricular models revealed a relationship between language in social studies curriculum and learning.

At KIPP: Star, instruction in U.S. history was divided between Grades 7 and 8. The eighth-grade U.S. history scope and sequence was quite traditional, a listing of American cultural traditions, customs, and assumptions to be preserved and disseminated. Within this scope and sequence was the illusion of inclusion in terms of gender and ethnicity issues, but the line item statements were based on the assumption of one point of view and resulted in gaps. For example, Lincoln was viewed as the savior of the Union; but nothing was included concerning Lincoln's primary focus of maintaining the Union even if that meant preserving slavery.

The curriculum also lacked the depth and breadth necessary to meet the national, state, and district standards satisfactorily. The lack of depth resulted in student and parent ambivalence, as well as loss of teacher morale. Even though the two eighth-grade U.S. history teachers conformed to the curriculum, no more than $72 \%$ of the students achieved scores considered at or above grade level. Additionally, the instructors relied heavily on textbooks to create manageable calendars of instruction presumably aligned with the standards and the end-of-year examinations.

KIPP: STAR was also an example of the disconnection between teachers' learning preferences and students' learning preferences. One complaint echoed by parents was that the school failed to appreciate the history of Harlem, the seat of the Harlem Renaissance, Malcolm X's proverbial living room, and home to a national research library dedicated specifically to the African diaspora. Parents believed that use of community resources might result in connecting students to the curriculum.

During the 2008-2009 school year, an Africentric U.S. history curriculum was implemented. Neither antiEurocentric nor solely pro-African, the Africentric curriculum was inclusive of the African diaspora within the United States and thereby inclusive of culturally diverse populations within U.S. classrooms. The following criteria were used to determine what was included in the new curriculum:

1. The scope is not solely African but seeks to undermine a racist hegemony that benefits Whites to the detriment of those determined as Other.

2. The curriculum supports and includes epistemological positions that are divergent from the normative.

3. Valid knowledge is not limited to what can be "linguistically articulated" (Abdi, 2006, pg. 17) due to the belief that an over reliance on sensory perception restricts knowledge. 
4. The curriculum is composed of body, mind, and spirit so that the objective and subjective coexist without contradiction.

Marzano and Kendall's (2007) revision of Bloom's taxonomy was incorporated to ensure an understanding of what students enter a class knowing, what they learn as a result of teaching, and the ways in which a properly structured curriculum can be used to navigate the journey from retrieval to internalization of a self-system. Marzano and Kendall (2007) included motivation and metacognition in the taxonomy as integral factors in successful learning. The three components of motivation are importance, efficacy, and emotional response. Students must first view information as important and relevant within their contexts. Students must be convinced they have the competence, command, and reserve to acquire the knowledge and to augment their comprehension of the information positively. Then, students must have optimistic and confident responses to the information presented.

The final curriculum consisted of eight units of study, spanning U.S. history from western expansion prior to the Civil through present day. Each unit detailed not only the content material but also the specific reading, writing, oral presentation, and critical thinking skills to be emphasized. During the 2008-2009 school year, students received instruction in U.S. history 2-1/2 days per week; in 2009-2010, instruction was increased to 5 days a week.

Assessment objectives were derived from the students' needs, parents' expectations, and school goals. Three-question quizzes were given twice a week, interim assessments occurred at the end of each 9-week period, and unit tests were the culminating assessments. Teacher-created assessments were also specific to the feature of history being studied. For example, in the historic portion, knowledge of analysis of primary documents was assessed. In sociology, assessment concerned the roles of people in institutions and the effects of interpersonal relationships on institutions were assessed. In geography, location and the effects of location on culture, economics, and government were assessed. In religion and art, students were assessed on the similarities and differences across cultures.

Standardized assessment consisted on the New York State Social Studies Test, usually scheduled each year in June. The test consists of three parts administered in two 90-minute sessions. Content consists of intermediatelevel critical ideas and performance benchmarks identified in state and district learning standards and in the curriculum adopted by the New York Board of Regents. The test is an assessment of knowledge in seven social studies standards: world history, United States and New York history, geography, citizenship, economics, civics, and government.

\section{METHOD}

A mixed methods quasi-experimental correlational retrospective study was conducted to examine the effects of an Africentric U.S. history curriculum on self-efficacy, emotional connection to curricular design, and academic achievement of Black students on standardized social studies assessments. Two hypotheses were used as the basis of this study:

$\mathbf{H}_{1}$ : $\quad$ A positive correlation exists between an Africentric U.S. history curricular model and end-of-year social studies scores for eighth-grade students at the KIPP: STAR College Preparatory Charter School.

$\mathbf{H}_{2}$ : $\quad$ A positive correlation exists between an Africentric U.S. history curricular model and self-efficacy for Black students in the eighth-grade class at the KIPP: STAR College Preparatory Charter School.

A nonequivalent group design was adopted to compare the use of a Eurocentric curricular design for the 2006-2007 and 200-2008 school years with implementation of the Africentric curricular design in 2008-2009 and 2009-2010.

The population for the study consisted of a total of 217 eighth-grade students from four consecutive school years beginning with 2006-2007, 97\% of whom were African, African American, or Hispanic. Students' scores on the New York State Social Studies Test were collected from the New York State Education Department Web site. Only aggregated data were available for the 2007 examination; individual scores were available for the 2008, 2009, and 2010 tests. 
Eighty parents were also selected through convenience sampling to participate in the study. At least 10 parents from each of the four school years being compared were selected. A total of 41 parents responded to the invitation to participate, but only 39 parents completed the online questionnaire.

The cross-sectional questionnaire was designed to elicit parental perceptions of (a) students' experiences over time; (b) students' emotional connections; and (c) students' perceived valence, expectancy, and instrumentality of both the Eurocentric and Africentric U.S. history curricular models. A pilot study was conducted to test the validity and reliability of the questionnaire. The final questionnaire consisted of 10 open-ended questions and 15 Likert-type scale questions in five categories: (a) definition and differentiation between the two curricula, (b) emphases of the curricula, (c) criteria for judging curricular proficiency, (d) emotional responses to the emic perspective of U.S. history, and (e) implications and conclusions for curriculum design.

Quantitative data were analyzed using paired $t$-tests, MANOVAs, multivariate $F$-tests, Tukey HSD tests, and Games-Howell Post Hoc comparisons. Questionnaire responses were categorized into parent tree nodes of content relevance, valence, expectancy, and instrumentality. An alternate analysis was also performed to elicit meaning statements or clusters emerging within the data. Questionnaire data were analyzed using Spearman rank order correlation coefficient and descriptive analysis procedures. Two correlation tests (corrected and uncorrected), critical one-sided and two-sided tests, and $z$-tests were performed to reduce the probability of a Type I error.

\section{RESULTS AND DISCUSSION}

For Hypothesis 1, multivariate and $t$-tests revealed that after implementation of the Africentric curriculum, a significant difference existed between students' performance levels, perceived self-efficacy, and emotional connection to the curriculum. Students who achieve the self-system level of learning, indicated by high feelings of self-efficacy, have higher achievement on assessments (Marzano \& Kendall, 2007). One-way ANOVAs between 2007 and 2010 data and between 2008 and 2010 data were also conducted. Results of the post hoc comparison indicated students receiving the Africentric curriculum achieved significantly higher on the New York State Social Studies Test than students who received the Eurocentric curriculum.

Hypothesis 2 was tested by analyzing responses to the parent questionnaire. Responses to the Likert-type scale questions indicated parents strongly linked the Africentric curriculum to their children's self-efficacy and to their emotional response and connection to the curriculum. Responses to open-ended questions indicated parents whose children received instruction in the Eurocentric model perceived cultural deficits in the curriculum. These parents would have changed the curriculum to be more inclusive of minorities. Parents whose children received instruction in the Africentric model were satisfied with the new curriculum.

Hypothesis 1 indicates that the implementation of an Africentric U.S. history curriculum is strongly and positively correlated to higher achievement on the New York State Social Test. Hypothesis 2 indicates that the implementation of an Africentric U.S. history curriculum is a contributing factor in the improvement in student selfefficacy and students' emotional connections to the curriculum. The results must not be viewed as coincidental but as indications of an effective strategy effective for minimizing and eventually closing the achievement gap.

In current efforts to close the achievement gap, the effects of purposeful curriculum redevelopment cannot be ignored. Although the assumption of the prevailing doctrine is that the current curriculum is somehow un-raced because it is stoked in the history of the United States, U.S. history curriculum has been overwhelmingly Eurocentric and psychologically oppressive to minorities in the United States (Abdi, 2006; Asante, 2003; Barret \& Koenker, 2008; Loewen, 2007).

The contention in the present study is that all U.S. history curricula is race-based but can become more comprehensive through inclusion of the stories of the races previously ignored or marginalized, in this case, Blacks. However, modification of the curriculum is not solely a Black need for validation. Creating a language of cultural competence focused on the deficit of information results in the continued dominant culture of White superiority if recognition of joint success is disregarded. Research has also shown the value of including ethnic-centered curriculum to empathize with cultures and races without societal privilege (Shockley, 2009). Thus, in rethinking 
history, we must rewrite history, not telling students lies but including true perspectives and holistic standpoints for more accurate views of past events.

We must also teach critical thinking. Students must learn to question if the available perspectives are truly the only perspectives available or if other options remain hidden. Prior research has indicated a positive correlation between student achievement, self-efficacy, and the implementation of critical thinking within a rigorous curriculum (Abrami et al., 2008). An Africentric U.S. history curriculum inherently includes critical thinking skills because of the utilization of the revised learning taxonomy (Marzano \& Kendall, 2007) as the basis for the hierarchy of learning and questioning. The results of the present study show critical thinking is a contributing factor in increasing achievement for all students.

\section{CONCLUSION}

Although students of color are achieving at higher levels than previously attained, they have continued to be outperformed in all areas of academics by their White and Asian counterparts (David et al., 2006). As Lincoln (1858) once affirmed that America could not survive with a population half slave and half free, the United States educational system cannot improve without honest dialogue concerning the causes of the achievement gap and reasonable solutions to minimize the gap. Students must be taught to think critically about the information they are given and even more critically about the information that may be withheld. If the objective of education is to produce citizens who will contribute positively to the nation and the world, the American history curriculum must be reevaluated and recreated. An Africentric U.S. history curriculum is a total history through which all students may engage and grow.

\section{AUTHOR INFORMATION}

Worokya Duncan, Ed.D is a professional educator and entreprenuer with over 14 years of experience, offering vast classroom experience, a Doctoral-level education, a great deal of energy, and a commitment to students. Over the course of her career, she has taught both elementary and middle school students in a variety of subjects, including United States History and Science. Her efforts undoubtedly extend beyond academics. I work hard to instill a sense of school pride, building community awareness, and motivating students to set higher standards. In addition to general education, her teaching experience encompasses inclusion classes. With all of her students, she takes time to connect with each one, demonstrating genuine sensitivity. She has a distinguished record in teaching and technical innovation achieved through conceptualization, development, and implementation of flexible delivery style learning techniques; expertise in applying sophisticated quantitative and qualitative research methodologies demonstrated in working towards successful completion of Ed.D.; and a visionary, goal-driven work ethic, combined with solid team collaboration competencies and individual strengths utilizing sound follow-through and detail orientation to plan and achieve projects from concept to successful completion. Dr. Duncan married to a wonderful man, Bryan, and we have three children- Jabari (8), Kimoni (4), and Zariah (2). For her undergraduate degree, she attended Duke University. While there, she double majored in Public Policy Studies and Political Science, and minored in African American Studies. Upon graduation, she matriculated into the Divinity School at Duke University, with a focus was on Liberation and Feminist Theology. After working in municipal bond industry, she knew her call was elsewhere. As her mother and grandmother were teachers, it was in her blood. E-mail: dec@duncaneducationalconsultants.com.

\section{REFERENCES}

1. Abdi, A. (2006). Eurocentric discourses and African philosophies and epistemologies of education: Counter-hegemonic analyses and responses. International Education, 36(1), 15-31. Retrieved from http://search.ebscohost.com.ezproxy.apollolibrary .com

2. Abrami, P.C., Bernard, R.M., Borokhovski, E., Wade, A., Surkes, M.A., Tamim, R., \& Zhaing, D. (2008). Instructional interventions affecting critical thinking skills and dispositions: A stage 1 metaanalysis. Review of Educational Research (78)1102-1134. Retrieved from EBSCOhost.

3. Asante, M. (2003). Africa and Africans in Antiquity. Research in African Literatures, 34(3), 178. Retrieved October 13, 2008. DOI: 10.1353/ral.2003.0056 
4. $\quad$ Asante, M. (2008). The afrocentric manifesto. Cambridge, United Kingdom: Polity Press.

5. Barret, J., \& Koenker, D. (2008). The saga of history 492: the transformation of working-class history in one classroom. Labour , 61, 181-215. Retrieved from http://find.galegroup.com.ezproxy.apollolibrary.com/ips/start.do?prodId=IPS

6. Darling-Hammond, L. (2010). The flat world and education: how America's commitment to equity will determine our future. New York, NY: Economic Policy Institute and Teachers College

7. David, J. L., Woodworth, K., Grant, E., Guha, R., Lopez-Torkos, A., \& Young, V. M. (2006). Bay area KIPP schools: A study of early implementation (First-Year Report 2004-05). Menlo Park, CA: SRI International.

8. James, T. (2007). A content analysis of three curriculum models: Africentric, eurocentric, and multicultural. Retrieved from ProQuest Dissertations \& Theses database (AN: 35812 )

9. KIPP Foundation. (2008). Welcome to KIPP, the knowledge is power program. Retrieved from WWW.KIPP.org

10. KIPP: STAR. (2010). Success through teamwork, achievement and accountability. Retrieved from Www.KIPPstar.org

11. Lincoln, A. (1858). A house divided against itself cannot stand. Washington, DC: National Center for Public Policy Research.

12. Loewen, J. (2007). Lies my teacher told me: Everything your American history textbook got wrong. New York, NY: Touchstone.

13. Marzano, R., \& Kendall, J. (2007). The new taxonomy of educational objectives. New York, NY: Corwin Press.

14. Shockley, K. (2009). A researcher "called" to "taboo" places? A burgeoning research method in Africancentered education. International Journal of Qualitative Studies in Education, 22(2), 163-176. doi:10.1080/09518390701706682

15. Zwick, R., \& Green, J. (2007). New perspectives on the correlation of sat scores, high school grades, and socioeconomic factors. Journal of Educational Measurement, 44(1), 23-45. doi:10.1111/j .1745-

3984.2007.00025.x 